\title{
Improvement of sheep fecundity by treatment with antisera to gonadal steroids
}

\author{
R. B. Land, B. A. Morris*, G. Baxter, Marjorie Fordyce and Janet Forster
}

A.R.C. Animal Breeding Research Organisation, Dryden Field Laboratory, Roslin, Midlothian EH25 9PS, and *Division of Clinical Biochemistry, Department of Biochemistry, University of Surrey, Guildford, Surrey GU2 $5 X H, U . K$.

(Presented as the Arthur Walpole Memorial Lecture for the Society for the Study of Fertility, Nottingham, 1982)

\begin{abstract}
Summary. Sera from sheep immunized against oestrone (Group $\mathrm{E}_{1}$ ), oestradiol (Group $\mathrm{E}_{2}$ ), androstenedione (Group $\mathrm{A}$ ) and testosterone (Group $\mathrm{T}$ ) were given to ewes singly or as a mixture (Group $M$ ) of all 4 types as a single intravenous injection at the time of the start of mating. The number of lambs produced, the numbers of eggs shed and the display of oestrus were recorded. The ovulation rates were 1.8 in Group $E_{1}, 2 \cdot 1$ in Group $\mathrm{E}_{2}, 1.6$ in Group A, 1.8 in Group $\mathrm{T}$ and 2.1 in Group $\mathrm{M}$ compared with 1.3 for the controls $(P$, variation among groups, $<0.001)$ in the first oestrous cycle. The effect persisted in those animals not conceiving to the first mating-1.3 in Group A, 1.8 in Group $\mathrm{E}_{1}, 1.9$ in Group $\mathrm{E}_{2}$ and 2.0 in Group $\mathrm{M}$ compared with 1.3 for the controls; all of the ewes in Group $T$ conceived to mating at a single oestrus. The mean number of lambs born alive per ewe treated was 1.1 for Group A, 1.3 for Group $E_{1}, 1 \cdot 3$ for Group $E_{2}, 1.5$ for Group T, 1.5 for Group $M$ and 1.0 for the controls. The increase in the number of lambs born was due to a higher proportion giving birth to twins $(P<0.01)$; no ewe gave birth to triplets. High conception rates were recorded for all treatments.
\end{abstract}

\section{Introduction}

Prolificacy, the number of young born per parturition, is a key component of the productivity of farm animals. In sheep it may be improved genetically by crossing or selection and environmentally by the provision of extra nutrients, but to date no technique of improvement based on pharmacological intervention at or around the time of mating has found widespread acceptance in practice for this or indeed any domestic species. Hunter (1980) concludes that the lack of precision of response and lower incidence of fertilization in animals treated with gonadotrophins may act to prevent significant increases in flock fecundity (the number of young born per female allocated to be mated). Most of the variation in sheep fecundity is the result of variation in the number of eggs shed (see Hanrahan \& Quirke, 1982) and natural genetic variation in ovulation rate has been reported to arise from variation in the sensitivity of gonadotrophin release to the feedback effects of gonadal steroids (Land, 1976). The artificial modification of such feedback may be an effective way to improve fecundity.

Active immunization of sheep against various steroids changes the feedback balance in favour of additional ovarian activity; immunization against androstenedione (Scaramuzzi, Davidson \& Van Look, 1977), oestradiol and oestrone (Scaramuzzi, Martensz \& Van Look, 1980) and testosterone (Scaramuzzi, Baird, Martensz, Turnbull \& Van Look, 1981) all caused ovarian hyperplasia. However, the responses reported have tended to be variable, excessive and associated with reduced fertility (conception rate). 
An alternative approach would be to use a pharmacological antisteroid such as clomiphene which may be used in this way in women (see Cox, 1975). A preliminary study confirmed the feasibility of this but showed that clomiphene was only weakly anti-oestrogenic in sheep in the circumstances studied (Land \& Scaramuzzi, 1979).

A third option is the passive immunization of sheep at the time of mating by the injection of sera from other immune sheep. Such a treatment would potentially combine the advantages of known antisteroidal activity of the antisera with the dose control and short-term effects of the antisteroidal compound. It would also offer the possibility of mixing sera to give a combination of low activity against each of a range of steroids so that the best control of ovulation rate could be achieved without changes in the equilibrium of any one steroid (Land, 1979).

The elimination of positive feedback by injection of anti-oestradiol sera demonstrated the feasibility of modifying steroid-gonadotrophin equilibria by passive immunization (Fairclough, Smith \& Peterson, 1976). Treatments of sheep with antisera to androstenedione, oestrone, oestradiol and testosterone and a mixture of the four increase the ovulation rate (Pathiraja, 1982) and we have now studied the use of such antisera to improve fecundity.

\section{Materials and Methods}

\section{Sheep}

The 151 mature Welsh Mountain sheep studied were kept outside at grass (A.B.R.O. Dryden Field Laboratory) with supplementary feed as dictated by normal husbandry.

\section{Antisera}

4-Androsten-3,17-dione (androstenedione), 1,3,5(10)-oestratrien-3 $\beta$-ol-17-one (oestrone), 1,3,5(10)-oestratrien-3,17 $\beta$-diol (oestradiol-17 $\beta$ ) and 4-androsten-17 $\beta$-ol-3-one (testosterone) were purchased from Steraloids Ltd (20a Chichester Road, Croydon, U.K.). The derivatives for immunogen preparation were: androsten-4-en-3,17-dione-7 $\alpha$-carboxyethyl thioether, synthesized by the method of Weinstein, Lindner, Friedlander \& Bauminger (1972); oestradiol-6-carboxymethyloxime was oxidized to give oestrone-6-carboxymethyloxime (Kohen, Bauminger \& Lindner, 1975); oestradiol-6-carboxymethyl-oxime by first synthesizing the 6-oxo derivative (Longwell \& Wintersteiner, 1940) and converting this to the oxime (Dean, Exley \& Johnson, 1971); oestradiol-3carboxymethyl-oxime was prepared directly from oestradiol by the method of Rao \& Moore (1977); and testosterone-3-carboxymethyl-oxime was also synthesized by the method of Rao \& Moore (1977).

These carboxy derivatives were conjugated to egg albumen (General Reagent Grade, BDH, Poole) by the mixed anhydride reaction of Erlanger, Borek, Beiser \& Lieberman (1957). The only departure from the published method was that the conjugates were not precipitated with hydrochloric acid after dialysis. The proportion of derivative molecules bound was determined for each conjugate by adding trace amounts of tritiated steroid to the reaction mixture in the preparation of the derivative and was found to be between 10 and $15 \mathrm{~mol}$ steroid per mol ovalbumen (mol. wt 45000 ).

Castrated male Suffolk cross-bred sheep were used for antibody production and each was primed with $5 \mathrm{mg}$ conjugate: the oestrone, oestradiol-6-CMO and testosterone conjugates were each injected into 2 sheep, the oestradiol-3-CMO conjugate was injected into another 3 animals, and, because of the initially low response, the androstenedione conjugate was injected into 6 sheep.

An aqueous solution of each conjugate was emulsified with non-ulcerative Freund's complete adjuvant (B. A. Morris, Guildhay Antisera, Division of Clinical Biochemistry, University of Surrey, Guildford) and injected intramuscularly. After a suitable, but variable, interval, a boosterdose of $2 \cdot 0-2 \cdot 5 \mathrm{mg}$ of the same batch of conjugate in incomplete adjuvant was injected by the same 
route, and the sheep were bled from the jugular vein 9 days later. Samples were taken from the animals approximately every 2 weeks when the titres were appropriate. Approximately $500 \mathrm{ml}$ blood were collected from each animal into a sterile bottle, using sterile needles and cannulae, and allowed to clot overnight at $4^{\circ} \mathrm{C}$. The following morning, the antiserum was harvested by aspiration and, after centrifugation at $4^{\circ} \mathrm{C}$ and $1300 \mathrm{~g}$ for $20 \mathrm{~min}$, was stored deep frozen.

The antisera to androstenedione, oestrone and testosterone were each a mixture of the sera raised in 2 sheep, the antiserum to oestradiol was a mixture from 4 of the 5 sheep ( 1 treated with 6and 3 with the 3-CMO conjugate).

Characterization. Titre and specificity of the various antisera were measured by radioimmunoassay (Abraham, 1975).

Titre. The titre was estimated by the addition of $0.1 \mathrm{ml} 2$-fold serial dilutions of each antiserum to $0.1 \mathrm{ml}$ phosphate gelatin assay buffer $(0.1 \%$ gelatin in $0.05 \mathrm{M}-\mathrm{PBS} \mathrm{pH} 7.5)$ with $0.1 \mathrm{ml}$ fixed mass of relevant radioactively labelled steroid (Amersham \& New England Nuclear; sp. act. 53-108 $\mathrm{Ci} / \mathrm{mmol})$.

The reaction volume was then incubated overnight at $4^{\circ} \mathrm{C}, 1 \mathrm{ml}$ dextran T-70 charcoal (Pharmacia) suspension ( $25 \mathrm{mg}$ dextran $: 250 \mathrm{mg}$ charcoal in $100 \mathrm{ml}$ assay buffer) was then added and incubated for a further $40 \mathrm{~min}$ at $4^{\circ} \mathrm{C}$ before centrifugation at $1100 \mathrm{~g}$ for $15 \mathrm{~min}$. The supernatant containing bound steroid was decanted into $10 \mathrm{ml}$ miniria 20 scintillation fluid (Koch-Light), mixed and counted.

The final dilution of antiserum in the reaction volume that bound $50 \%$ of the labelled steroid was defined as the titre and was $1: 144000$ for androstenedione, 1:1540000 for oestradiol, $1: 480000$ for oestrone and $1: 276000$ for testosterone. The specific activities of the added tracers were $45,53,153$ and $102 \mathrm{Ci} / \mathrm{mol}$ for androstenedione, testosterone, oestradiol and oestrone, respectively, and the added masses were $125,105,36$ and $55 \mathrm{fmol}$, respectively.

Specificity. The specificity of the steroid antisera was tested by performing cross-reactivity studies with the present 4 steroids and progesterone.

Dose-response curves of each steroid with the four antisera were compared and the percentage cross reactivities were:

\begin{tabular}{lccccc} 
Antiserum to: & \multicolumn{5}{c}{ Nominal steroid } \\
& $\mathrm{A}$ & $\mathrm{E}_{1}$ & $\mathrm{E}_{2}$ & $\mathrm{~T}$ & $\mathrm{P}$ \\
Androstenedione (A) & - & 0.03 & $<0.01$ & 0.2 & 0.04 \\
Oestrone $\left(\mathrm{E}_{1}\right)$ & $<0.01$ & - & 1.0 & $<0.01$ & 0.1 \\
Oestradiol $\left(\mathrm{E}_{2}\right)$ & $<0.01$ & 6.8 & - & 0.1 & $<0.01$ \\
Testosterone $(\mathrm{T})$ & 1.0 & $<0.01$ & 0.2 & - & 0.03
\end{tabular}

With only approximate information regarding the ultimate titre desired, the dose was a compromise between that considered desirable on the basis of earlier information and the number of animals available for treatment; the doses given were $20 \mathrm{ml}$ for androstenedione and oestrone antisera, $7.5 \mathrm{ml}$ for oestradiol and $23 \mathrm{ml}$ for testosterone antisera. One quarter of each of the four individual steroid doses was combined to make the antiserum 'mixture'.

Each of the animals to be treated was given a single injection (i.v.) of antiserum on the day of the start of mating with a fertile ram. Control animals were left untreated.

\section{Experimental programme}

The ovulation rate of each sheep was recorded before and after mating and the durations of the oestrous cycle in which it was mated and of any subsequent cycles were recorded. To measure the general effects of the stage of the oestrous cycle at the time of injection and to simulate commercial husbandry conditions, animals were treated and mating started on a chosen day without regard to 
the oestrous cycle. To reduce the possibility that the stages of the oestrous cycle represented at the time of treatment might be reduced as a result of partial synchrony of the oestrous cycle by the introduction of the ram around the time of the start of the breeding season, the sheep were divided into two flocks. Both flocks were exposed to rams on the same day: one flock was treated and became eligible for mating from that day but treatment and mating were postponed for 8 days in the other.

Raddled vasectomized 'teaser' rams were introduced on 8 October and oestrus was recorded in one flock from the 10th and in the other from the $18 \mathrm{th}$. Within flocks animals were allocated in rotation as they showed oestrus for no treatment (controls) or for treatment with antiserum to androstenedione (Group A), oestrone (Group $E_{1}$ ), oestradiol (Group $E_{2}$ ), testosterone (Group T) or mixed sera (Group $M)$. The number of eggs shed at the oestrus before treatment was recorded as the number of fresh (red) corpora lutea observed on the ovaries at laparoscopy 3-13 days after oestrus. Treatment was given on 27 October in one flock and 4 November in the other. Oestrus was then checked twice daily and ewes exhibiting oestrus were brought in for mating with fertile rams. Oestrous ewes were penned singly with fertile rams and at least one mating was recorded before the ewes were mixed with fertile rams for possible further mating at that oestrus. Returns to heat and remating were recorded through the use of keelmarks. If a ewe did not show oestrus during the 17 days before the designated start of mating, mating was postponed for 17 days so that the ovulation rate before mating could be recorded. The number of eggs shed at the time of the first and any subsequent mating with a fertile ram was recorded at laparoscopy 3-13 days after mating up until 27 December 1980.

The number of lambs per ewe was recorded at the time of lambing.

Statistical methods. Differences among groups in the number of ewes with particular numbers of corpora lutea or lambs were tested by $\chi^{2}$. Individual groups were compared to the control group by the use of Fisher's exact test which gives the sum of the probabilities of the observed or any more extreme distribution arising by chance. The problems of interpreting the results of multiple tests were acknowledged throughout.

\section{Results}

Ovulation. As shown in Table 1, there were no statistically significant differences among the groups before treatment when the number of single versus the number of multiple ovulations was compared for the various groups. After treatment, however, the mean ovulation number varied from 1.26 for the control group to $2 \cdot 1$ for those in Groups $E_{2}$ and $M$ and $\chi^{2}$ test showed the variation among groups to be statistically significant $(P<0.001)$. The principal effect of treatment was to increase the incidence of twin ovulations (Table 1). The comparison of individual groups in turn with the control group using Fisher's exact test showed that all treatments significantly increased the ovulation rate although the statistical significance of the effect in Group A was marginal.

Although there were relatively few animals not conceiving to the first mating after injection the mean ovulation rate at the return to oestrus was higher in all treated groups than in the controls. In Groups $E_{1}$ and $M$ it was indistinguishable from that of the first ovulation after treatment while in Groups $A$ and $E_{2}$ it regressed $0 \cdot 2-0 \cdot 3$ eggs towards the level of 1.25 of the control ewes (a mean indistinguishable from that at the first ovulation after the start of mating).

Conception. Tests of statistical significance of the differences among the groups for conception at first mating indicated that the higher conception rate of the ewes in Group $T$ was probably real (Table 1). The removal of the Group $T$ values from the comparison of all groups gave a $\chi^{2}$ value of 6.4 for 4 d.f. $(P>0.1)$, compared to 13.8 for 5 d.f. $(P<0.05)$ when Group T values were present, confirming the similarity of the other 5 groups.

Number of lambs. The total number of lambs present at the time of lambing was greater for treated than control ewes (Table 2). No ewe gave birth to triplets, and the $\chi^{2}$ test of the number of 
Table 1. The number of eggs shed, oestrus and conception of ewes given antisera to androstenedione (Group A), oestrone (Group $E_{1}$ ), oestradiol (Group $E_{2}$ ), testosterone (Group T), a mixture of the 4 sera (Group $\mathrm{M}$ ) and of control ewes

\begin{tabular}{|c|c|c|c|c|c|c|c|}
\hline & Control & Group A & Group $E_{1}$ & Group $E_{2}$ & Group T & Group M & $P$ (test $\S)$ \\
\hline No. of ewes & 27 & 24 & 29 & 31 & 18 & 22 & \\
\hline \multicolumn{8}{|l|}{ Before treatment } \\
\hline \multicolumn{8}{|l|}{ After treatment } \\
\hline $\begin{array}{l}\text { Distribution of } \mathrm{CL}^{*}\left\{\begin{array}{l}2 \\
3\end{array}\right. \\
P\end{array}$ & $\begin{array}{l}7 \\
0\end{array}$ & $\begin{array}{c}13 \\
0 \\
0 \cdot 04\end{array}$ & $\begin{array}{c}22 \\
1 \\
<0 \cdot 001\end{array}$ & $\begin{array}{c}17 \\
7 \\
<0.001\end{array}$ & $\begin{array}{c}14 \\
0 \\
<0.001\end{array}$ & $\begin{array}{c}14 \\
4 \\
<0.001\end{array}$ & $\begin{array}{l}<0.001\left(\chi^{2}\right) \\
(\mathrm{FE})\end{array}$ \\
\hline $\begin{array}{l}\text { Mean ovulation rate of ewes } \\
\text { ovulating }\end{array}$ & $1 \cdot 26$ & 1.57 & 1.83 & $2 \cdot 11$ & $1 \cdot 78$ & 2.05 & \\
\hline $\begin{array}{l}\text { No. of ewes conceiving at one } \\
\text { oestrus }\end{array}$ & 19 & 18 & 23 & $17 \dagger$ & 18 & 18 & $<0.05\left(\chi^{2}\right)$ \\
\hline$P$ & & 0.7 & 0.5 & $0 \cdot 3$ & 0.01 & 0.5 & (FE) \\
\hline $\begin{array}{l}\text { No. of ewes with extended } \\
\text { oestrous cycle }\end{array}$ & 0 & 1 & 0 & 3 & 0 & 0 & \\
\hline \multicolumn{8}{|l|}{ Return to oestrus } \\
\hline (1) & 6 & 4 & 1 & 3 & 0 & 0 & \\
\hline Distribution of $C L \ddagger\{2$ & 2 & 2 & 5 & 9 & 0 & 4 & \\
\hline$(3$ & 0 & 0 & 0 & 1 & 0 & 0 & \\
\hline Mean ovulation rate & 1.25 & $1 \cdot 33$ & 1.83 & 1.85 & - & $2 \cdot 00$ & \\
\hline
\end{tabular}

* One value missing for Group $\mathbf{M}$.

$\dagger$ One of the 17 conceived to a first mating after an extended oestrous cycle.

‡ One ewe not observed in Group $E_{2}$.

$\S$ FE, Fisher's exact test.

Table 2. The number of lambs carried and the number born alive to ewes treated with antisera to androstenedione (Group A), oestrone (Group $E_{1}$ ), oestradiol (Group $E_{2}$ ), testosterone (Group T), a mixture of the 4 sera (Group $M$ ) and to control ewes

\begin{tabular}{|c|c|c|c|c|c|c|c|c|}
\hline & & Control & Group A & Group $E_{1}$ & Group $E_{2}$ & Group T & Group M & $P$ (test) \\
\hline No. of ewes & & 27 & 24 & 29 & 31 & 18 & 22 & \multirow{7}{*}{$\begin{array}{l}<0.01\left(\chi^{2}\right) \\
(\mathrm{FE})\end{array}$} \\
\hline Barren ewes & & 2 & 1 & 1 & 3 & 0 & 1 & \\
\hline Distribution of & $\{1$ & 20 & 14 & 12 & 12 & 7 & 5 & \\
\hline lambs at term & $\{2$ & 5 & 9 & 16 & 16 & 11 & 16 & \\
\hline$P(1$ versus 2$)$ & & & 0.3 & 0.03 & 0.03 & 0.08 & $<0.001$ & \\
\hline $\begin{array}{l}\text { Ewes failing to lamb } \\
\text { normally at term }\end{array}$ & & 0 & 2 & 1 & 2 & 2 & 1 & \\
\hline $\begin{array}{l}\text { Mean no. of lambs per } \\
\text { pregnant ewe }\end{array}$ & & $1 \cdot 20$ & 1.39 & 1.57 & 1.57 & 1.61 & $1 \cdot 76$ & \\
\hline Distribution of & $\int 0$ & 3 & 4 & 3 & 3 & 2 & 3 & \multirow{7}{*}{ (FE) } \\
\hline live lambs & $\{1$ & 18 & 12 & 12 & 12 & 8 & 4 & \\
\hline$P$ (live versus dead) & $(2$ & 4 & 7 & 13 & 13 & 8 & 14 & \\
\hline $\begin{array}{l}\text { Mean no. of lambs born } \\
\text { alive per ewe lambing }\end{array}$ & & 1.04 & $\begin{array}{l}0.7 \\
1.24\end{array}$ & $\begin{array}{c}1 \\
1.41\end{array}$ & $\begin{array}{c}1 \\
1.46\end{array}$ & $\begin{array}{c}1 \\
1.50\end{array}$ & $\begin{array}{c}1 \\
1.80\end{array}$ & \\
\hline $\begin{array}{l}\text { Mean no. of lambs born } \\
\text { alive per ewe treated }\end{array}$ & & 0.96 & 1.08 & $1 \cdot 31$ & $1 \cdot 25$ & $1 \cdot 33$ & 1.45 & \\
\hline Gestation length (days) & & 148 & 149 & 149 & 148 & 149 & 149 & \\
\hline s.d. & & $2 \cdot 7$ & $2 \cdot 6$ & $3 \cdot 1$ & 1.9 & $3 \cdot 1$ & $2 \cdot 3$ & \\
\hline
\end{tabular}


ewes with single versus twin lambs indicated real differences among groups. Comparison of individual groups with the controls indicated that the superiority was real for all except Group A.

Of the total of 216 lambs present $184(85 \%)$ were born alive. There was no indication of any differences in the proportion of live lambs among the groups (Table 2). Four of the dead lambs resulted from 2 ewes which aborted shortly before lambing, and 12 were from 6 ewes which died with symptoms of pregnancy toxaemia shortly before the expected time of lambing. All 8 ewes were treated with sera but with 69 of the treated ewes and only 5 of the untreated ones bearing twins, 8 and 0 is the most likely allocation of a total of 8 failures (Fisher's exact test) indicating no real difference.

There were no differences among the 6 groups in the number of ewes failing to give birth to any live lambs or in lamb mortality (Table 2). The statistically significant differences among groups in live lambs born per ewe originally allocated for treatment were therefore similar to those for the number of lambs per pregnant ewe at lambing. The ewes in Group M produced 1.5 lambs per ewe treated compared to an average of only 1 lamb for the controls.

Gestation length. The mean gestation length for ewes in each group was 148 or 149 days (Table 2); neither the mean nor the variation (Table 2) was affected by the treatment.

Ovum viability. The ovulation of viable ova, their fertilization, implantation and gestation was estimated as the proportion of corpora lutea represented as lambs. This, together with the proportion of ewes showing oestrus and ovulating at the expected time after treatment gives an index of ewe fertility which is presented in Table 3 (all ewes). The index shows that, when the stage of the oestrous cycle at the time of treatment is ignored, ewes in Groups $\mathrm{E}_{2}$ and $\mathrm{M}$ had depressed fertility while those in Group $\mathrm{T}$ had apparently increased fertility.

Table 3. Index of ewe fertility calculated as (no. of lambs per corpus luteum at ovulation at the expected time) $\times$ (proportion of ewes ovulating at expected time) following treatment during the early and luteal phases of the oestrous cycle (Days 1-12) and the follicular phase of the cycle (Days 13-18) and at all times

together with the mean ovulation rate of those ovulating after an oestrous cycle of 15-20 days

\begin{tabular}{|c|c|c|c|c|c|c|c|c|c|}
\hline \multirow[b]{2}{*}{ Treatment } & \multicolumn{3}{|c|}{ Days 1-12 } & \multicolumn{3}{|c|}{ Days $13-18$} & \multicolumn{3}{|c|}{ All ewes } \\
\hline & No. & Fertility & CL & No. & Fertility & $\mathrm{CL}$ & No. & Fertility & $\mathrm{CL}$ \\
\hline Control & 20 & 0.65 & $1 \cdot 30$ & 7 & 0.63 & $1 \cdot 14$ & 27 & 0.65 & $1 \cdot 26$ \\
\hline Group A & 14 & 0.59 & 1.69 & 10 & 0.79 & 1.40 & 24 & 0.67 & 1.57 \\
\hline Group $E_{1}$ & 19 & 0.69 & 1.83 & 10 & 0.51 & 1.78 & 29 & 0.63 & 1.81 \\
\hline Group $E_{2}$ & 18 & 0.46 & 2.07 & 13 & 0.20 & $2 \cdot 11$ & 31 & 0.35 & 2.08 \\
\hline Group $\Upsilon$ & 14 & 0.85 & 1.85 & 4 & 0.86 & 1.75 & 18 & 0.85 & 1.82 \\
\hline Group M & 13 & 0.53 & $2 \cdot 00$ & 9 & 0.36 & $2 \cdot 20$ & 22 & 0.45 & 2.06 \\
\hline
\end{tabular}

Statistical analysis of the two components of the index, the proportion of ewes returning to oestrus normally and the proportion of corpora lutea represented as lambs, showed that the variation in the proportion of normal oestrous cycles among groups was statistically significant, $P$ $<0.05$. The proportion was lower for ewes in Groups $\mathrm{E}_{2}$ and $\mathrm{M}$ than for the controls $(P=0.05$ and 0.005 respectively).

The differences in ovum viability were marked $(P<0.001)$. The ewes in Group T showed a significantly higher proportion of corpora lutea represented as lambs than did those of the control group $(P=0.019)$. The lower proportion surviving in Group $\mathrm{E}_{2}$ than in the controls approached statistical significance $(0.05<P<0 \cdot 1)$.

Effect of the stage of the oestrous cycle. The number of eggs shed and the fertility of the return to oestrus following treatment is represented in Table 4 relative to the day of the oestrous cycle when the individuals were treated. The incidence of abnormal oestrous cycles and the fertility of the 
Table 4. The number of corpora lutea observed in the ovaries of sheep ovulating after treatment with antisera to androstenedione (Group $A$ ), oestrone (Group $E_{1}$ ), oestradiol (Group $E_{2}$ ), testosterone (Group $\mathrm{T}$ ), a mixture of the 4 sera (Group M) and controls (C) according to the day of the oestrous cycle when treated

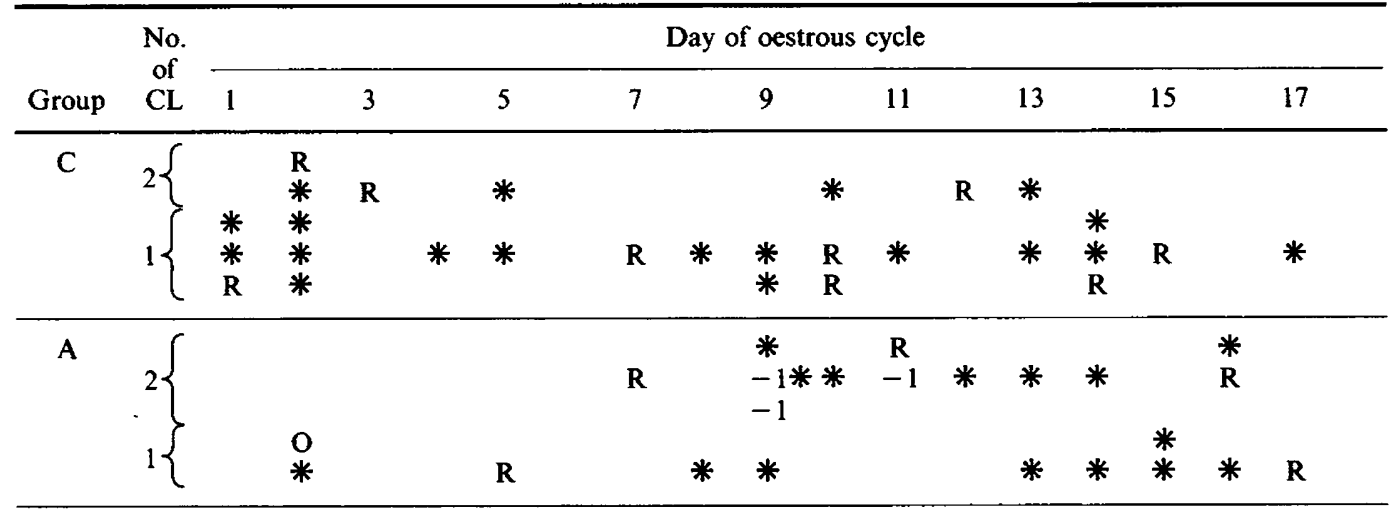

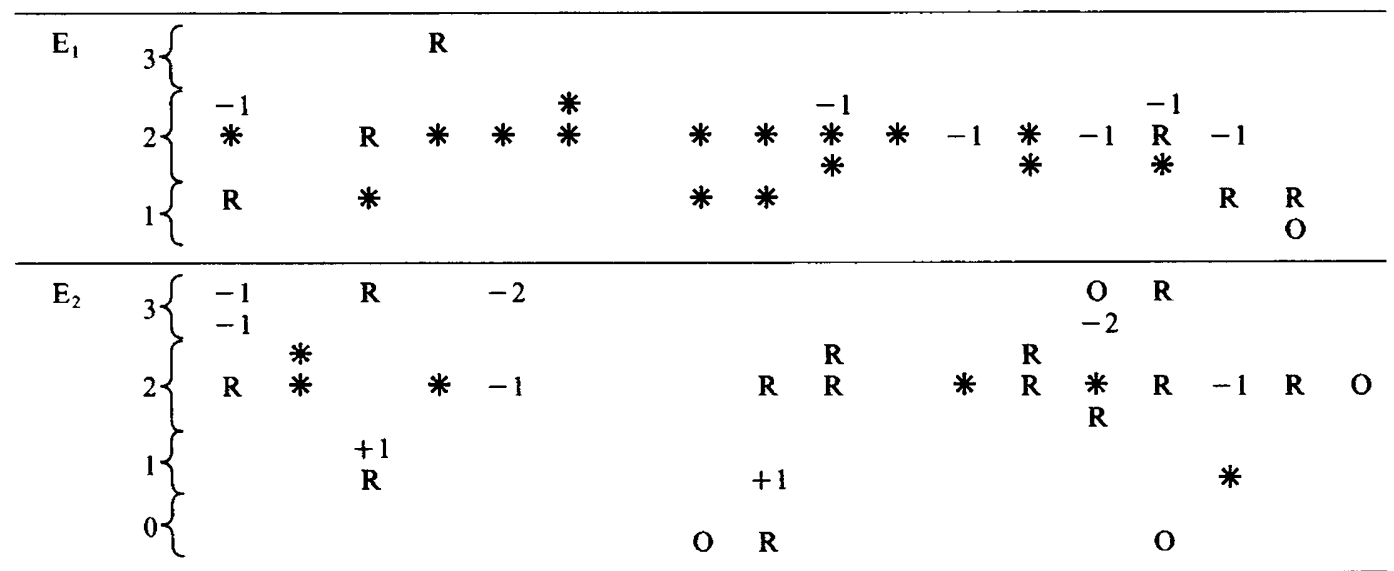

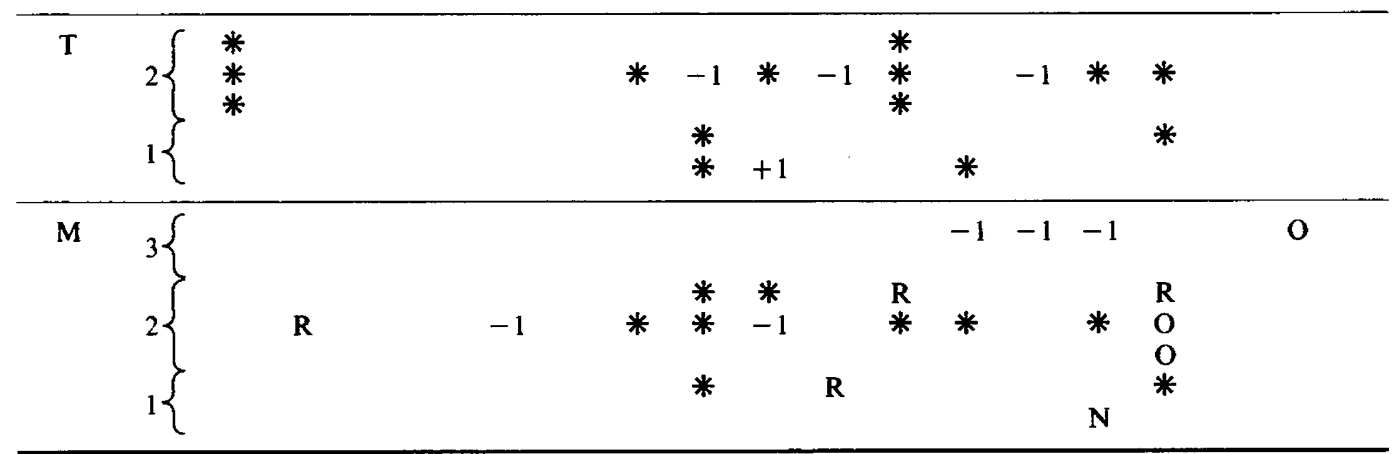

Each individual ewe is represented by a symbol: the ewes which conceived and in which all CL observed are represented as lambs are represented by $*$; ewes which conceived but gave birth to a number of lambs different from that of the CL are indicated by a sign and number; ewes failing to conceive are denoted by $R$; ewes returning to oestrus $<12$ or $>20$ days after the previous oestrus by $\mathrm{O}$; not observed, $\mathrm{N}$.

return to oestrus but not the number of eggs shed were apparently greater in Groups $\mathrm{E}_{2}$ and $\mathrm{M}$ when the serum was given late in the oestrous cycle. None of the three characteristics seemed to be affected by the time of treatment relative to mating in any of the other 4 groups. This was quantified by subdividing the data in Table 3 to give a separate index for the fertility of ewes treated 
during the early and luteal (Days 1-12) and the follicular (Days 13-18) phase of the oestrous cycle. This index was only 0.2 for Group $E_{2}$ and 0.4 for Group $M$ when treated during the follicular phase compared to 0.6 for the controls in general. The number of animals was too small to demonstrate statistical significance for either component of the index of fertility for Groups $\mathrm{E}_{2}$ or $\mathbf{M}$.

By contrast, the number of eggs shed after treatment during the early and luteal phase was similar to that following treatment in the follicular phase; the largest difference between treatment early and late in the oestrous cycle was 0.29 corpora lutea (Tables 3 and 4 ). The long-term nature of the effect on ovulation rate was confirmed by the high ovulation rate of animals returning to oestrus.

The linearity of the response to mixed sera. The response to the mixture of the 4 sera was compared to the average effects of the 4 individual sera. The values of $\chi^{2}$ for the comparison of all single sera (average) versus the mixture Group $\mathrm{M}$ were computed for several traits as follows:

$\begin{array}{lccccc} & \text { Group } M & \text { Average } & \chi^{2} & \text { d.f. } & \\ \text { No. of corpora lutea } & 2.05 & 1.80 & 2.8 & 2 & P>0 \cdot 1 \\ \text { No. of lambs born alive per ewe lambing } & 1.60 & 1.40 & 5.6 & 2 & P<0.1 \\ \text { No. of lambs per ewe allocated } & 1.68 & 1.46 & 3.2 & 2 & P>0.1 \\ \text { No. of live lambs per ewe allocated } & 1.45 & 1.24 & 5 \cdot 2 & 2 & P<0 \cdot 1\end{array}$

The mixture tended to lead to a higher response than that which would be predicted from the linear effects of its components. Although the superiority was not statistically significant, $(0 \cdot 1>P$ $>0.05$ ), an extra 0.2 lambs would be of very real practical significance.

Sex of lambs. The number of female lambs per male lamb varied from 1.5 in Group $M$ to 0.8 in Group A. There were no statistically significant differences among the groups in the proportion of the two sexes.

\section{Discussion}

The use of antisera to steroids increased the prolificacy of sheep. Ewes given a mixture of antisera gave birth to $50 \%$ more live lambs than did control ewes. The improved prolificacy arose from an increase in the proportion of twin relative to single pregnancies, not from an occasional ewe giving birth to many lambs. The schedule for treatment was the simplest possible-ewes were given a single injection on the day of the start of mating without any control of the oestrous cycle.

The high conception rates achieved show that the passive immunization may be used to induce high prolificacy without any loss in fertility or with an apparent increase in fertility (Group T).

Some of the differences between the treatment groups may have arisen from the physiological functions of the steroid to which the immune sera were prepared, others from the volume of antisera and hence the titre of antibodies given. Anti-oestradiol serum has been shown to block the oestrogen-induced preovulatory discharge of LH (Fairclough et al., 1976) and the response of ovariectomized ewes to the injection of oestrogen (Scaramuzzi, 1975); the ewes in Group $E_{2}$ in the present experiment showed the highest proportion of extended oestrous cycles and had the lowest index of the fertility. The index of fertility in the other three groups given antisera to single steroids was similar to that of the control ewes but the ewes given the mixture of sera showed reduced fertility. It is therefore reasonable to argue that the reduction in the fertility of Group $M$ ewes arose from the anti-oestradiol component.

The small effect of androstenedione on ovulation rate in the present study is likely to be the result of using too small a dose of serum. The results of active immunization (see Scaramuzzi et al., 1977) and passive immunization (Pathiraja, 1982) all show that antibodies to androstenedione may raise the number of eggs shed. The use of higher doses would merit investigation. 
By contrast with the lower fertility of the ewes given antisera to oestradiol, those given antisera to testosterone showed higher fertility. All of the 18 fertile ewes in this experiment and 20 in another trial conceived to mating at a single oestrus. Such a combination of higher prolificacy and higher fertility would have considerable implications for the agricultural industry even though the mechanism of action is not known. It has, however, been shown that even short periods of exposure to an asynchronous uterus may cause the death of embryos and a steroid-induced lethal uterine product has been postulated (Wilmut \& Sales, 1981). The anti-testosterone serum may interfere with the production of such a protein or lead to greater synchrony between the embryo and the uterus.

The stage of the oestrous cycle at the time of injection did not affect the response to antisera to androstenedione, oestrone or testosterone within the limits of the size of the experiment. However, one would expect there to be a stage of the oestrous cycle, beyond which the favourable effects declined. For the anti-oestradiol and mixed sera the disadvantageous effect of reduced fertility was greater when the injection was given late in the oestrous cycle. However, the favourable effects of all sera persisted through to the time of return to oestrus for those ewes that did not conceive to the first mating. The injection of sheep, about 3 days before the introduction of the ram might therefore be appropriate especially if there were a particular reason to use anti-oestradiol serum, e.g. the ease with which high titres of antibodies can be raised against oestradiol. A mixture of sera would have as great or greater effect per unit of serum than single sera and would be cheaper to produce.

The doses of anti-testosterone and anti-oestrone serum might be useful in practice, but if antiandrostenedione serum were to be used a higher dose would probably be required. The use of a mixture of antisera led to the highest average number of lambs. Further trials would be needed to determine the most appropriate mixture but, relative to the optimum dose of individual steroids, proportions of $40: 20: 20: 20$ for testosterone, androstenedione, oestrone and oestradiol might be a reasonable starting point. Passive immunization may be appropriate in practice in high-cost systems of husbandry. Of equal importance, it offers a route to study controlled twinning in cattle as well as sheep and may stimulate the search for cheaper pharmacological alternatives.

We thank R. D. Preece for technical assistance, the staff at the Dryden Field Laboratory for the detection of oestrus, mating and care of the sheep throughout, and G. E. Morley, Regional Steroid Laboratory, Epsom, who synthesized the immunogens.

\section{References}

Abraham, G.E. (1975) Characterization of anti-steroid antisera. In Steroid Immunoassay, pp. 67-78. Eds E. H. D. Cameron, S. G. Hillier \& K. Griffiths. Alpha Omega Publishing Ltd, Cardiff.

Cox, L.W. (1975) Infertility: a comprehensive programme. Br. J. Obstet. Gynaec. 82, 2-6.

Dean, P.D.G., Exley, D. \& Johnson, M.W. (1971) Preparation of 17ß-oestradiol-6-(O-carboxymethyl)-oxime-bovine serum albumin conjugate. Steroids 18, 593-603.

Erlanger, B.R., Borek, F., Beiser, S.M. \& Lieberman, S. (1957) Steroid-protein conjugates. I. Preparation and characterisation of conjugates of bovine serum albumin with testosterone and with cortisone. J. biol. Chem. 228, 713-727.

Fairclough, R.J., Smith, J.F. \& Peterson, A.J. (1976) Passive immunization against oestradiol- $17 \beta$ and its effect on luteolysis, oestrus and ovulation in the ewe. $J$. Reprod. Fert. 48, 169-171.

Hanrahan, J.P. \& Quirke, J.F. (1982) Results of supero- vulation egg transfer and selection for ovulation rate in sheep. Proc. Wld Congr. Sheep and Cattle Breeding, Christchurch. (In press.)

Hunter, R.H.F. (1980) Physiology and Technology of Reproduction in Female Domestic Animals. Academic Press, London.

Kohen, F., Bauminger, S. \& Lindner, H.R. (1975) Preparation of antigenic steroid-protein conjugates. In Steroid Immunoassay, pp. 11-32. Eds E. H. D. Cameron, S. G. Hillier \& K. Griffiths. Alpha Omega Publishing Ltd, Cardiff.

Land, R.B. (1976) The sensitivity of the ovulation rate of Finnish Landrace and Blackface ewes to exogenous oestrogen. J. Reprod. Fert. 48, 217-218.

Land, R.B. (1979) Improvement in gonadal function through modification of negative feedback. Annls Biol. anim. Biochim. Biophys. 19, 1569-1574.

Land, R.B. \& Scaramuzzi, R.J. (1979) A note on the ovulation rate of sheep following treatment with clomiphene citrate. Anim. Prod. 28, 131-134. 
Longwell, B.B. \& Wintersteiner, O. (1940) Estrogens with oxygen in Ring B. III. 6-keto- $\alpha$-estradiol. $J$. biol. Chem. 133, 219-229.

Pathiraja, N. (1982) Physiological basis of genetic variation in ovulation rate. Ph.D. thesis, University of Edinburgh.

Rao, P.N. \& Moore, P.H. (1977) Synthesis of new steroid heptens for radioimmunoassay. Part IV. 3-O-carboxymethyl ether derivatives of oestrogens. Specific antisera for radioimmunoassay of oestrone oestradiol$17 \beta$ and oestriol. Steroids 29, 461-469.

Scaramuzzi, R.J. (1975) Inhibition of oestrous behaviour in ewes by passive immunization against oestradiol173. J. Reprod. Fert. 42, 145-148.

Scaramuzzi, R.J., Davidson, W.G. \& Van Look, P.F.A. (1977) Increasing the ovulation rate of sheep by active immunisation against an ovarian steroid, androstenedione. Nature, Lond. 269, 817-818.

Scaramuzzi, R.J., Martensz, N.D. \& Van Look, P.F.A.
(1980) Ovarian morphology and the concentration of steroids and of gonadotrophins during the breeding season in ewes actively immunized against oestradiol-17ß or oestrone. J. Reprod. Fert. 59, 303-310.

Scaramuzzi, R.J., Baird, D.T., Martensz, N.D., Turnbull, K.E. \& Van Look, P.F.A. (1981) Ovarian function in the ewe after active immunization against testosterone. J. Reprod. Fert. 61, 1-9.

Weinstein, A., Lindner, H.R., Friedlander, A. \& Bauminger, S. (1972) Antigenic complexes of steroid hormones formed by coupling to protein through position 7: preparation from $\Delta^{4}-3$-oxosteroids and characterisation of antibodies to testosterone and androstenedione. Steroids 20, 789-812.

Wilmut, I. \& Sales, D.S. (1981) Effect on an asynchronous environment in embryonic development in sheep. J. Reprod. Fert. 61, 179-184.

Received 8 March 1982 